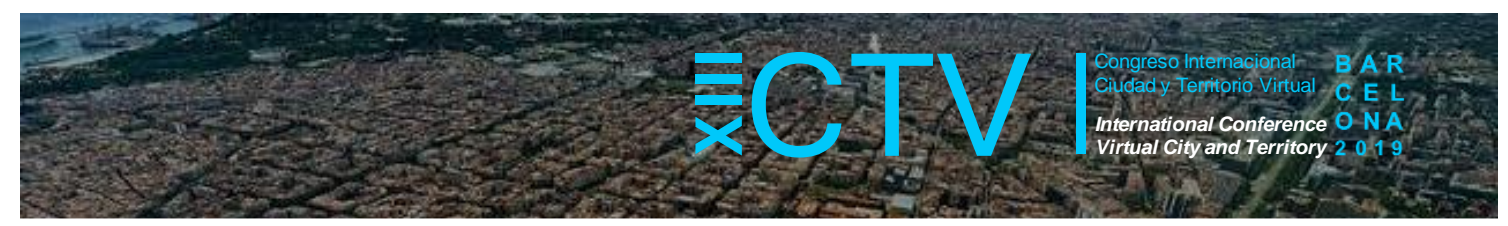

\title{
LA VULNERACIÓN DEL DERECHO DE LA MUJER A LA VIVIENDA EN ESPAÑA (2008-2018)
}

Bosch Meda, Jordi ${ }^{1}$ *

Remisión inicial: 2019-05-21; Remisión definitiva: 2019-10-15; Publicación: 2019-12-21

Citación: Bosch Meda, J. (2019). La vulneración del derecho de la mujer a la vivienda en España (20082018). En XIII CTV 2019 Proceedings: XIII International Conference on Virtual City and Territory: "Challenges and paradigms of the contemporary city": UPC, Barcelona, October 2-4, 2019. Barcelona: CPSV, 2019, p. 8413. E-ISSN 2604-6512. DOI http://dx.doi.org/10.5821/ctv.8413

\section{Resumen}

El objetivo de este artículo es analizar la dimensión física y económica de la exclusión residencial entre las mujeres en España durante el periodo 2008-2018. La investigación se basa fundamentalmente en la explotación de dos fuentes estadísticas: la Encuesta de Condiciones de Vida (ECV) llevada a cabo por el Instituto Nacional de Estadística (INE) y la Encuesta sobre Integración y Necesidades Sociales de la Fundación FOESSA (EINSFOESSA) de 2018. Los resultados anteriores se han complementado con datos de fuentes secundarias obtenidos a través de una revisión bibliográfica no exhaustiva. La principal aportación de este trabajo radica en el hecho que ofrece una visión completa y actualizada de un tema escasamente analizado como es la feminización de la exclusión residencial en España. Los resultados muestran de forma concluyente que el estallido de la burbuja residencial y la posterior recesión económica provocaron una grave crisis residencial que afectó con mayor intensidad a las mujeres. La dimensión económica de esta feminización de la exclusión residencial es particularmente visible en la evolución de la relación entre ingresos del hogar y costes residenciales. Durante todo el periodo 2008-2018, el esfuerzo económico de las mujeres para satisfacer sus costes residenciales, así como, por lo general, su tasa de sobresfuerzo económico, fueron superiores al de los hombres. Por ello, estos hogares tienen una mayor propensión a desarrollar estrategias residenciales orientadas a reducir los costes de su vivienda como, por ejemplo, el subarriendo de habitaciones, bajos consumos de electricidad, agua o calefacción, o una mayor movilidad residencial en busca de viviendas más asequibles. Al respecto, hay que destacar los mayores niveles de vulnerabilidad residencial que soportan los hogares monoparentales y aquellas mujeres que viven solas en alquiler. Esta peor situación de la mujer en el mercado residencial también queda reflejada en las condiciones físicas de la vivienda y su entorno. Los hogares encabezados por una mujer suelen sufrir con mayor frecuencia en su vivienda: problemas de insalubridad, escasez de luz natural, déficits de rehabilitación, y existencia de barreras arquitectónicas; y se ubican en barrios donde también son mayores las probabilidades de padecer problemas de contaminación, ruido, vandalismo y delincuencia. Ante esta realidad, resulta oportuno reflexionar sobre la eficacia del conjunto de documentos políticos y jurídicos que a nivel nacional e internacional exhortan a los gobiernos a garantizar el derecho de la mujer a una vivienda digna y adecuada. ¿Cómo puede explicarse que el derecho de la mujer a la vivienda en España haya alcanzado semejantes cotas de vulneración a pesar de la extensa relación de tratados y convenciones internacionales que lo protegen y que son de aplicación en el territorio español? Es evidente que no existen medidas suficientes que corrijan la feminización de la exclusión residencial en España. Es más, probablemente los recortes de gasto público que se han llevado a cabo en España tras la crisis no han hecho más que socavar las de por si débiles políticas de igualdad y de vivienda de nuestro país, y por extensión, ensanchar la brecha de género (gender gap) en materia de exclusión residencial. En este contexto, resulta obvio que es necesario superar el plano teórico-declarativo del reconocimiento del derecho a la vivienda y a la igualdad entre hombres y mujeres, y conseguir que estas políticas se implementen, se doten presupuestariamente con los recursos necesarios, y se evalúen.

\section{Abstract}

The objective of this article is to analyse the physical and economic dimension of housing exclusion among women in Spain during the 2008-2018 period. This research is based primarily on two statistical sources: The Survey on Living Conditions (ECV) carried out by the National Institute of Statistics (INE) and the 2018 Survey on Integration and Social Needs of the FOESSA Foundation (EINSFOESSA). The results have been complemented with data from secondary sources obtained through a non-exhaustive literature review. The main contribution of this work lies in the fact that it offers a complete and up-to-date vision of the feminization of housing exclusion in Spain, an issue that has been scarcely examined. The results show conclusively that the housing bubble bust and the subsequent financial crisis caused a severe

\footnotetext{
${ }^{1}$ Dr. Arquitecto, Diplomado en Gestión y Administración Pública, y Licenciado en Ciencias Políticas. Universidad
} Politécnica de Cataluña, UPC, http://orcid.org/0000-0001-7678-0953. * Correo de contacto: jorge.bosch@upc.edu 


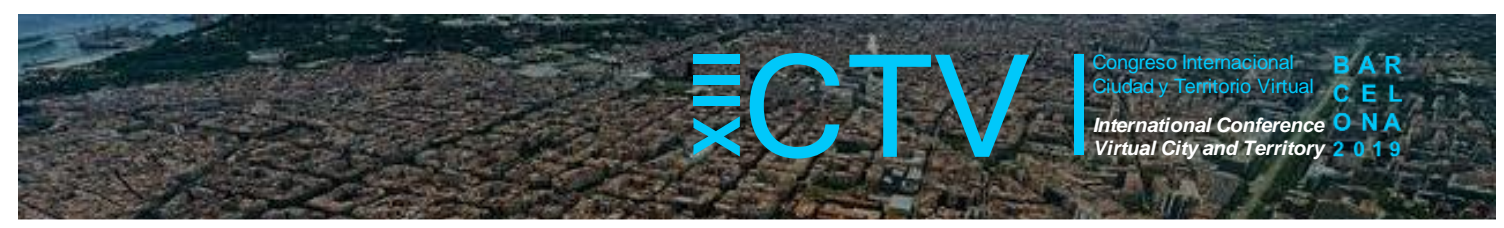

housing crisis that affected women more intensely. The economic dimension of this feminization of housing exclusion is particularly visible in the evolution of the relationship between household income and residential costs. During the 20082018 period, the housing cost burden and, in general, the housing cost overburden rate of women were higher than that of men. Therefore, these households have a greater propensity to develop strategies aimed at reducing the housing costs, such as the subletting of rooms, low consumption of electricity, water or heating, or greater residential mobility in search of more affordable dwellings. In this regard, it is worth highlighting the higher levels of housing vulnerability of singleparent households and single-person female households in the rented sector. The worse position of women in housing markets is also reflected in their physical housing conditions and its urban surroundings. Woman-headed households have a higher likelihood of living in non-barrier-free dwellings, in insanitary conditions, lacking of natural light, and with renewal needs. In addition, their dwelling is more likely to be located in urban areas with higher levels of pollution, noise, vandalism and crime. Given this reality, it is appropriate to ponder the effectiveness of all political and legal documents that call on governments to guarantee the right of women to decent and adequate housing at the national and international level. How can it be explained that the right of women to housing in Spain has reached such levels of violation despite the extensive relationship of international treaties and conventions that protect it and are applicable? There are not undoubtedly enough measures to correct the feminization of housing exclusion in Spain. Moreover, the cuts in public spending that took place in Spain after the crisis have undermined gender equality and housing policies, and by extension, widen the gender gap in housing exclusion. In this context, it is obvious that it is necessary to overcome the theoretical and declarative level of recognition of the right to housing and equality between men and women, and to ensure that these policies are appropriately budgeted, implemented, and monitored.

Palabras Clave: derecho a la vivienda; política de vivienda; perspectiva de género; exclusión residencial

Key words: Right to Housing; Housing Policy; Gender Perspective; Housing Exclusion

\section{Introducción}

A lo largo de los últimos veinte años, el problema de la vivienda ha ido ganando progresivamente importancia en España, tanto en el campo político como académico, a medida que las dificultades de los hogares para acceder y mantener su vivienda se incrementaban. Durante este periodo, lógicamente, la evolución de la exclusión residencial ha estado condicionada por los cambios políticos, demográficos y sociales que han tenido lugar y, sobre todo, por las diferentes etapas del ciclo económico.

Desde la segunda mitad de los años noventa hasta finales de 2007, el sector residencial español experimentó una intensa fase de expansión caracterizada por un intenso aumento del precio de la vivienda, y por un alto ritmo de construcción de nueva unidades residenciales y de operaciones de compraventa. Entre los principales factores que impulsaron el mercado, hay que destacar sobre todo cuatro: (i) la histórica caída de los tipos de interés, por debajo de la inflación en algunos años; (ii) la extraordinaria facilidad con la que las entidades financieras concedieron créditos y préstamos hipotecarios para la adquisición de vivienda; (iii) el fuerte crecimiento demográfico que experimentó la sociedad española en aquellos años, tanto en términos de población como en número hogares a causa de la inmigración y emancipación de los babyboomers nacidos a finales de los sesenta, principios de los setenta; (iv) y la bonanza económica que vivía el país, la cual, además de favorecer la reducción del desempleo en un contexto de incremento de población activa, creó un clima de optimismo económico absolutamente irracional. Todo ello generó, por un lado, un crecimiento considerable de la deuda hipotecaria, especialmente preocupante entre aquellos hogares que accedieron a la propiedad en el punto más álgido y, por otro, una creciente crisis de accesibilidad económica a la vivienda dado que el incremento de los costes residenciales no se vio compensado por una mejora equivalente en los salarios.

Sin embargo, la crisis financiera global que se inició en 2007 invirtió el ciclo económico, poniendo fin a la fase expansionista. En 2008 la economía española entró en recisión, el mercado de 


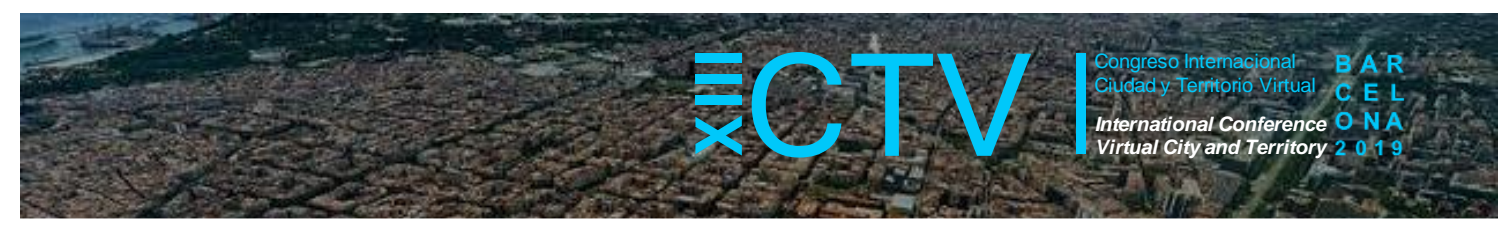

vivienda frenó bruscamente, y el desempleo empezó a subir con fuerza y, con ello, las dificultades de los hogares para hacer frente los costes de sus viviendas. De hecho, el estallido de la burbuja provocó un cambio de paradigma en materia de vivienda. Si durante los años de exuberancia el principal problema fue la creciente dificultad de accesibilidad económica de un segmento de la población que iba ensanchándose a medida que los precios subían, con la crisis los problemas de solvencia de los hogares para atender los gastos residenciales ocuparon su lugar.

No obstante, esta crisis residencial ha ido evolucionando a la vez que lo hacían los factores que determinan la situación en el mercado de vivienda de los hogares socioeconómicamente más vulnerables. Durante el periodo 2008-2013, la principal expresión de esta crisis residencial fueron las ejecuciones hipotecarias a causa fatídica combinación de elevados niveles de endeudamiento hipotecario de un segmento notable de los hogares propietarios y el grave deterioro de la economía española, en particular, del mercado de trabajo. En cambio, a partir de 2013, a pesar del inicio de una nueva fase de recuperación económica y de la creación de empleo, los problemas de solvencia de los hogares para satisfacer los costes de sus viviendas no remitieron sino que se concentraron sobre todo entre el segmento de alquiler. La expansión de los desahucios por impago de la renta fundamentalmente estuvo impulsada por cuatro factores: (i) el aumento de la demanda de vivienda en alquiler de los últimos años (tras el estallido de la burbuja las condiciones para acceder al crédito hipotecario se endurecieron, y también es muy probable que muchos hogares hayan optado por el alquiler ante la incertidumbre económica y laboral); (ii) la escasez de oferta de viviendas en este régimen; (iii) el mayor porcentaje de hogares en riesgo de exclusión social en este segmento del mercado residencial; (iv) y la extrema debilidad de las políticas de vivienda social y de ayudas al pago del alquiler de España. Además, en determinados municipios, el turismo ejerce una presión adicional sobre los precios del alquiler que se ha visto amplificada con la proliferación de apartamentos turísticos gracias a plataformas on-line como Airbnb.

En este contexto, el objetivo de este artículo es analizar la dimensión física y económica de la exclusión residencial entre las mujeres en España tras el estallido de la burbuja residencial y posterior crisis económica. Al respecto, dado que la literatura de un modo prácticamente unánime coincide en señalar la edad, la procedencia y el género como los principales ejes de desigualdad social, es lógico pensar que en cada uno de los periodos antes mencionados las diferentes formas de exclusión residencial han tenido una mayor incidencia y gravedad en aquellos hogares encabezados por una mujer.

Esta investigación se basa fundamentalmente en dos fuentes estadísticas: la Encuesta de Condiciones de Vida (ECV) llevada a cabo por el Instituto Nacional de Estadística (INE) y en algunas variables explotada por EUROSTAT (en cuyo caso se armoniza a nivel europeo bajo en nombre de European Survey on Income and Living Conditions, EU-SILC), mediante la cual podemos obtener una visión longitudinal de la exclusión residencial gracias a su periodicidad anual; y la Encuesta sobre Integración y Necesidades Sociales de la Fundación FOESSA (EINSFOESSA) de 2018, con la que podemos profundizar en la situación actual del problema de la vivienda en España desde una perspectiva de género. Asimismo, los resultados anteriores se han complementado con datos de fuentes secundarias obtenidos fundamentalmente a través de una revisión bibliográfica no exhaustiva del tema.

La principal aportación de este trabajo radica en el hecho que ofrece una visión completa y actualizada de la feminización de la exclusión residencial en España tras el estallido de la 


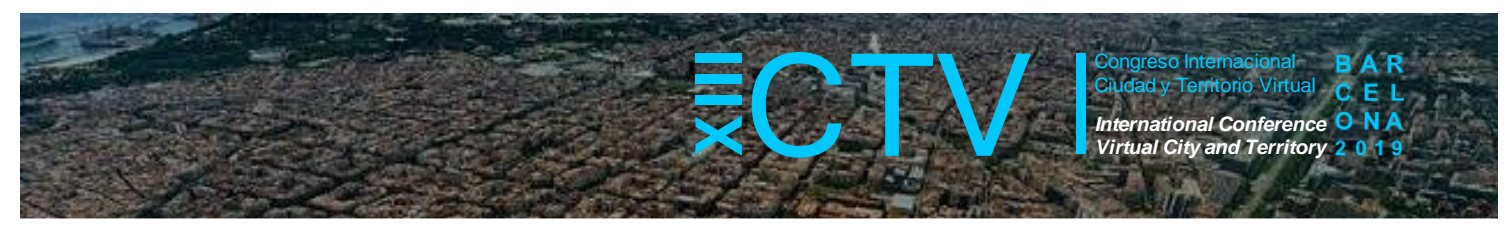

burbuja, lo cual debería facilitar el diseño e implementación de medidas específicas (targeted) para corregir esta problemática. En este sentido, es importante subrayar el escaso número de trabajos ( $p$. ej. Bosch, 2006) que han introducido la perspectiva de género en el análisis del problema de la vivienda en nuestro país.

\section{Mujer y vivienda: marco teórico}

El derecho de la mujer a la vivienda, así como la necesidad de incorporar la perspectiva de género en las políticas de vivienda goza desde hace tiempo de un amplio reconocimiento en la agenda política internacional, como queda de manifiesto, por ejemplo, en: el Pacto Internacional de Derechos Económicos, Sociales y Culturales (PIDESC) de 1966, ratificado por España en 1976; la Convención sobre la Eliminación de Todas las Formas de Discriminación contra la Mujer (CEDAW) adoptada por Naciones Unidas en 1979, y también ratificado por España en 1984; la Cuarta Conferencia Mundial sobre la Mujer de 1995, en la que se aprobó la Plataforma de Acción de Beijing; en todas las conferencias internacionales de Naciones Unidas sobre los asentamientos humanos, más conocidas como Hábitat; la Agenda 2030 de Desarrollo Sostenible, aprobada en 2015 por 197 países, entre los que se incluye España; la Carta Europea de Salvaguarda de los Derechos Humanos en la Ciudad (Saint-Denis, 2000); o la Carta-Agenda Mundial de Derechos Humanos en la Ciudad adoptada en Florencia a finales de 2011 bajo el impulso de la plataforma mundial Ciudades y Gobiernos Locales Unidos (CGLU).

No obstante, a pesar de este vasto reconocimiento, lamentablemente, la exclusión residencial de la mujer es una realidad en muchos países. Los sucesivos informes del Relator Especial de Naciones Unidas sobre el derecho de la mujer a una vivienda adecuada (p. ej. Kothari, 2006), los de las relatoras posteriores sobre la vivienda adecuada como elemento integrante del derecho a un nivel de vida adecuado (Rolnik, 2011; Farha, 2015), así como los publicados directamente por Naciones Unidas (p. ej. UN-Human Rights, 2012; UN-Habitat, 2014) y los relativos a las consultas regionales sobre este asunto (p. ej. UN-Habitat, 2005; Emanuelli, 2004) denuncian que las mujeres sufren un trato discriminatorio en todas las esferas esenciales para el disfrute de una vivienda adecuada a causa de un cúmulo de factores interrelacionados, entre los que cabe destacar: (i) el desigual acceso de la mujer a la educación y a las fuentes de ingresos; (ii) su inferior posición en los mercados de trabajo; (iii) sus mayores tasas de pobreza y exclusión social, (iv) las frecuentes barreras legales y sociales para acceder a la tierra, a la propiedad, a la herencia, al crédito y a los subsidios de vivienda; $(v)$ y la ausencia de programas nacionales para corregir esta discriminación. Numerosos estudios llevados a cabo fuera de la esfera de Naciones Unidas coinciden con este diagnóstico como, por ejemplo, los llevados a cabo en América Latina (p. ej. COHRE, 2010), Australia (p. ej. Tually et al., 2007), u otros de alcance global (p. ej. Kennett y Kam, 2010).

\section{La exclusión residencial de la mujer en España durante el periodo 2008-2018}

\subsection{La dimensión económica}

La evolución del esfuerzo económico a la vivienda en España desde el 2008 dibuja de forma nítida las fases de crisis y recuperación antes descritas (Figura 1). Entre los años 2008 y 2013, el esfuerzo económico a la vivienda, es decir, la proporción de ingresos que destinaban los 


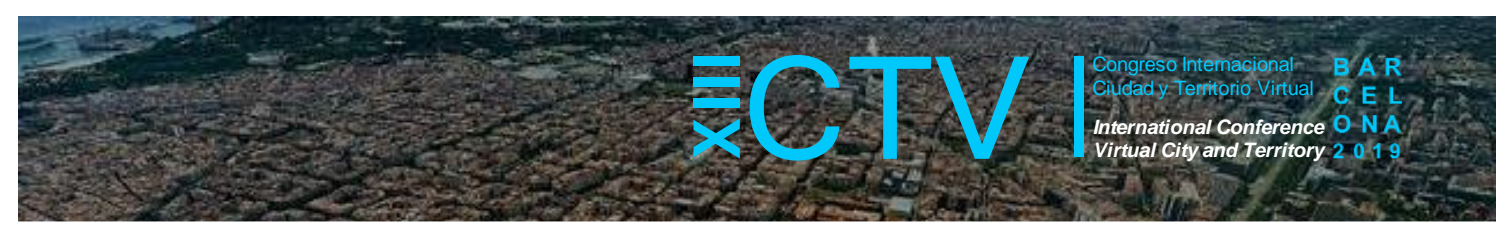

hogares a satisfacer los costes de la vivienda², subió con fuerza y posteriormente fue reduciéndose, siendo durante todo este periodo el de las mujeres siempre mayor que el de los hombres.

Figura 1. Evolución de la mediana de la distribución del porcentaje del total de costes de la vivienda respecto los ingresos del hogar por sexo, España 2008-2018

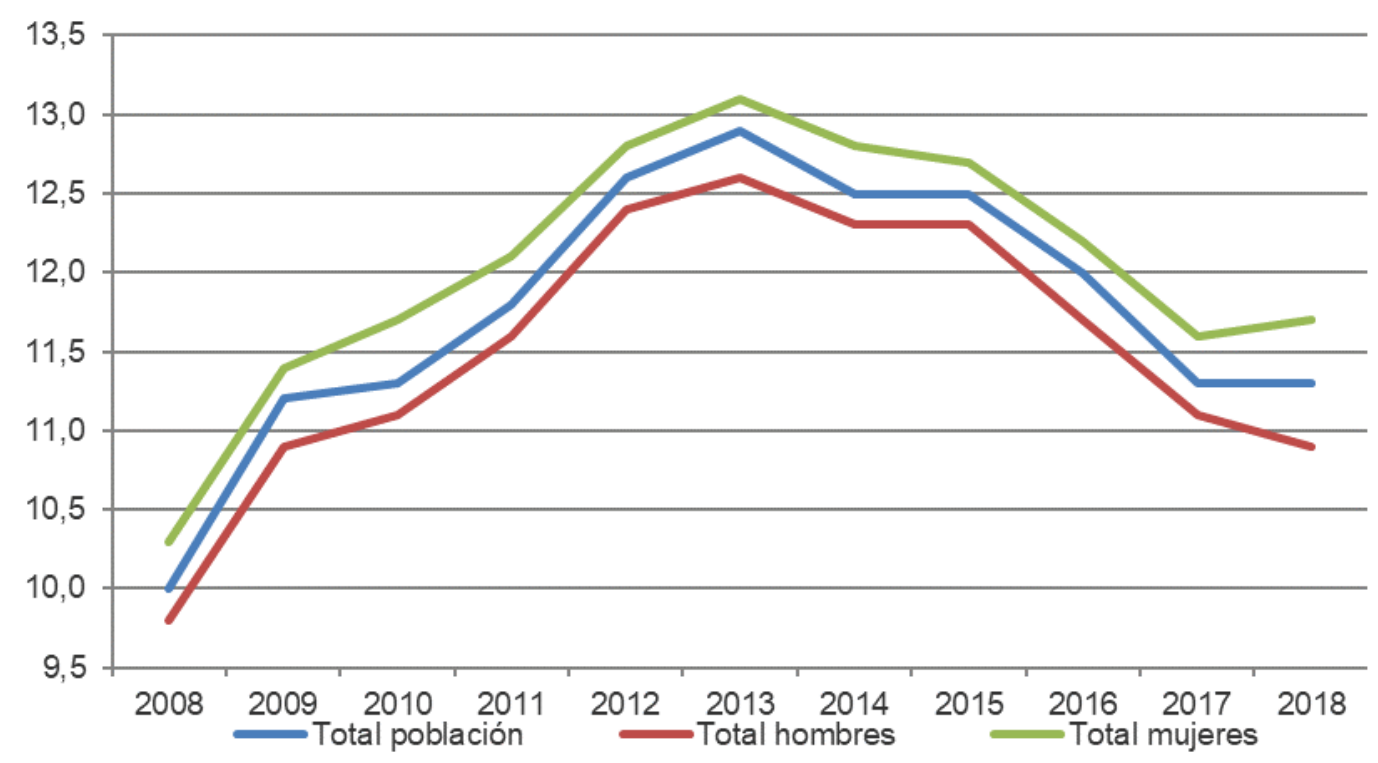

Fuente: European Survey on Income and Living Conditions (EU-SILC), EUROSTAT.

Figura 2. Evolución la población en situación de sobreesfuerzo económico a la vivienda por sexo, España 2008-2017

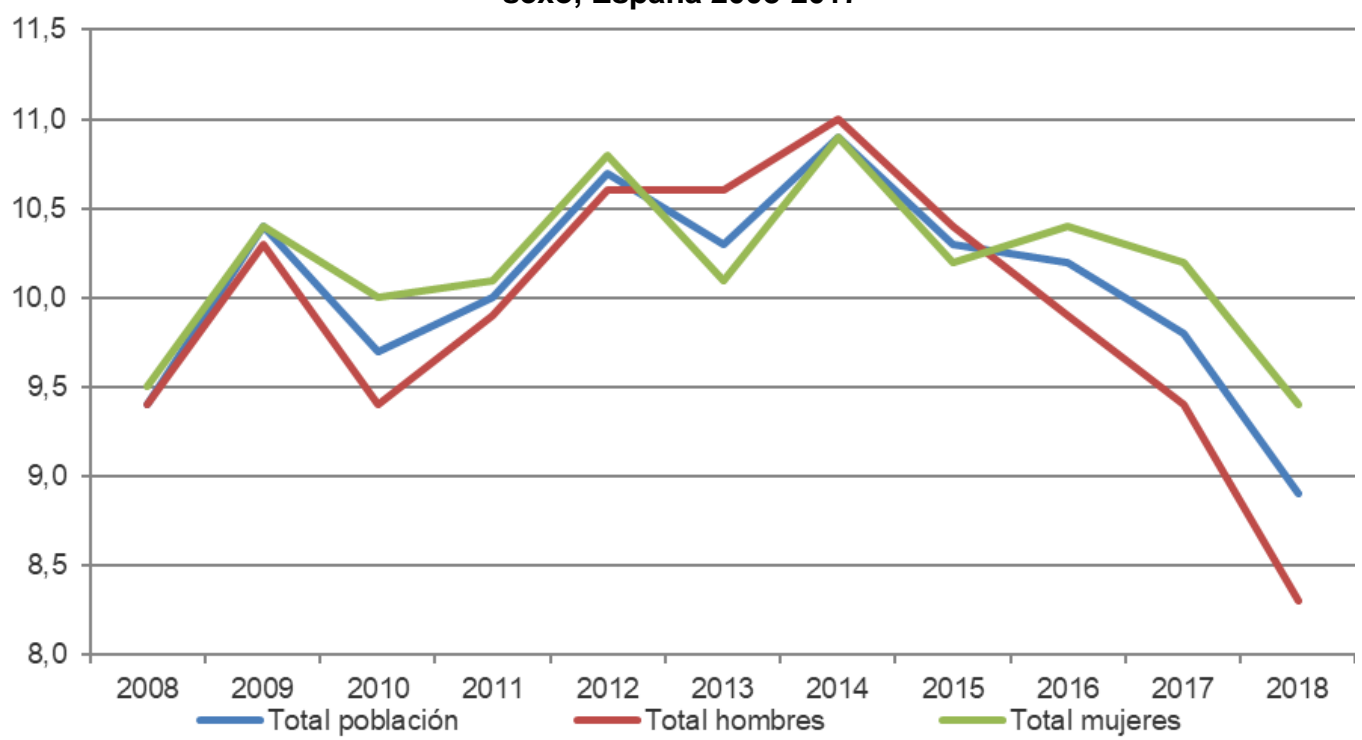

Fuente: European Survey on Income and Living Conditions (EU-SILC), EUROSTAT.

\footnotetext{
${ }^{2}$ Los costes residenciales están formados por el alquiler o la cuota hipotecaria sin la parte correspondiente a amortización del crédito hipotecario (la metodología de EUROSTAT considera este gasto ligado a un bien de consumo de naturaleza duradera), y por la totalidad del coste de los servicios de la vivienda, a saber, el servicio de agua, el impuesto de bienes inmuebles, la electricidad, el alcantarillado, el seguro del hogar, la recogida de basuras y otros impuestos municipales.
} 


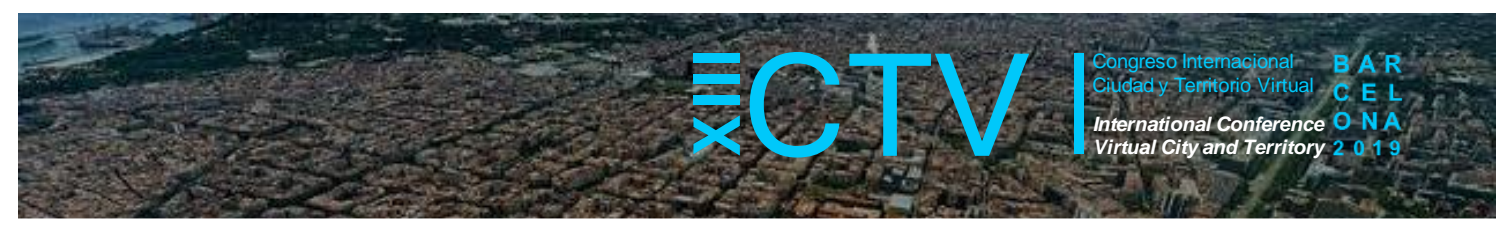

De un modo parecido, el comportamiento de la tasa de sobreesfuerzo económico a la vivienda, a saber, del porcentaje de población cuyos costes residenciales eran superiores al $40 \%$ de los ingresos del hogar reproduce las fases de crisis y recuperación. Entre 2008 y 2014 , este indicador tuvo una clara tendencia alcista y solo fue a partir de 2014 que empezó a remitir paulatinamente (Figura 2). Por sexos, el porcentaje de mujeres en situación de sobreesfuerzo económico fue siempre superior al de los hombres a lo largo de este periodo excepto en el bienio 2013-2014.

Figura 3. Evolución de esfuerzo económico medio a la vivienda por tipo de hogar y régimen de tenencia de la vivienda. España, 2008-2018

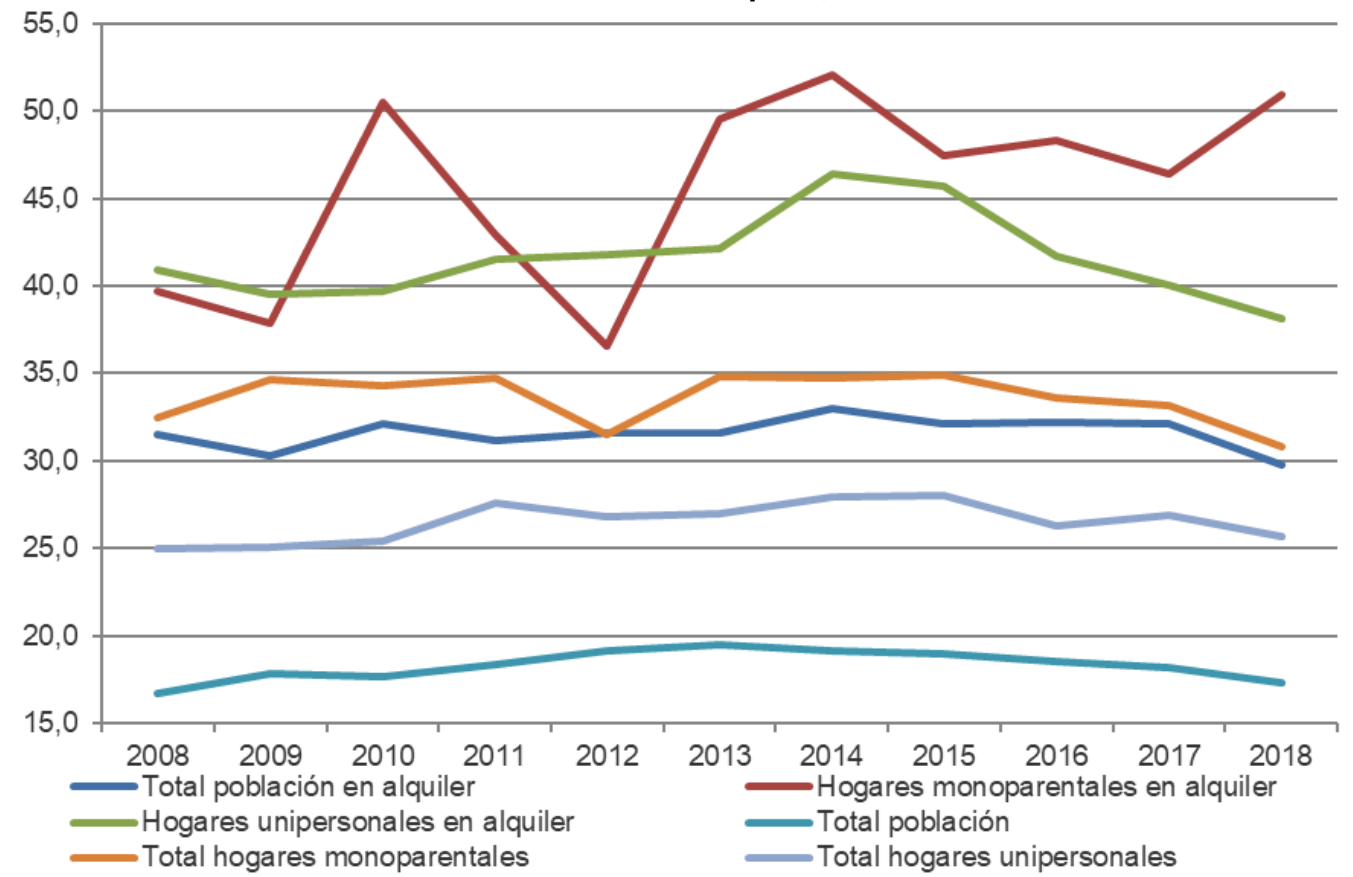

Fuente: European Survey on Income and Living Conditions (EU-SILC), EUROSTAT.

Otras variables que también se asocian con una peor relación entre costes residenciales e ingresos del hogar son la monoparentalidad, los hogares unipersonales y el alquiler, por lo que cuando estos factores de riesgo de exclusión económica a la vivienda se dan simultáneamente, las probabilidades de no poder satisfacer los costes residenciales se multiplican. Por ejemplo, el esfuerzo económico medio en el mercado de alquiler que deben realizar los hogares monoparentales y los unipersonales se situó a lo largo del periodo 2008-2017, por lo general, por encima del $40 \%$ de los ingresos (Figura 3 ), es decir, superó el umbral máximo por encima del cual se considera muy probable que una familia situada en los dos quintiles inferiores de renta no disponga de recursos suficientes para otras necesidades básicas como la comida, el transporte o la ropa. Al respecto, es importante tener presente que el esfuerzo económico medio de la población española que vive en alquiler es uno de los más elevados de toda Europa (Bosch, 2015, pág. 168).

La situación de los hogares monoparentales merece especial atención por su elevada vulnerabilidad. Entre los años 2008 y 2018, este tipo de hogares, con mucha mayor frecuencia que el conjunto de la población, han tenido retrasos en el pago de los gastos relacionados con su vivienda (Figura 4), y sufrido situaciones de pobreza energética (Figura 5). Al respecto, es importante tener presente que los hogares integrados por uno sólo de los progenitores están 


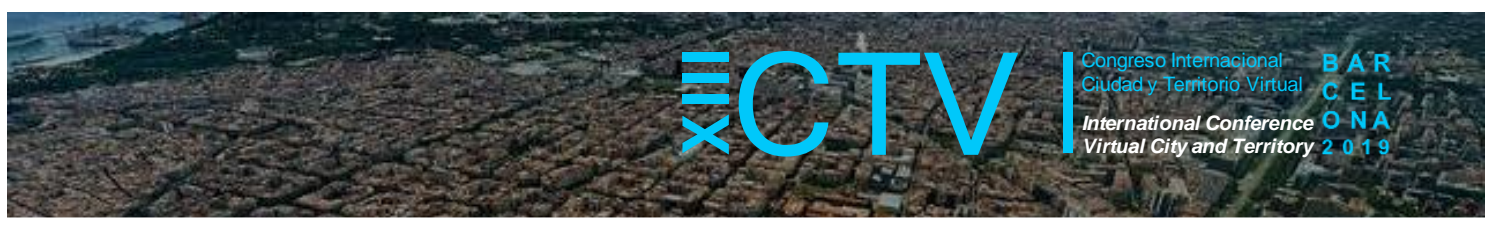

mayoritariamente encabezados por mujeres: en un $83 \%$ de los casos de acuerdo con la Encuesta Continua de Hogares de 2017.

Figura 4. Evolución del porcentaje de población que ha tenido retrasos en el pago de gastos relacionados con la vivienda principal (hipoteca o alquiler, recibos de gas, comunidad, etc.) en los últimos 12 meses, por sexo y tipo de hogar (monoparental). España, 2008-2018

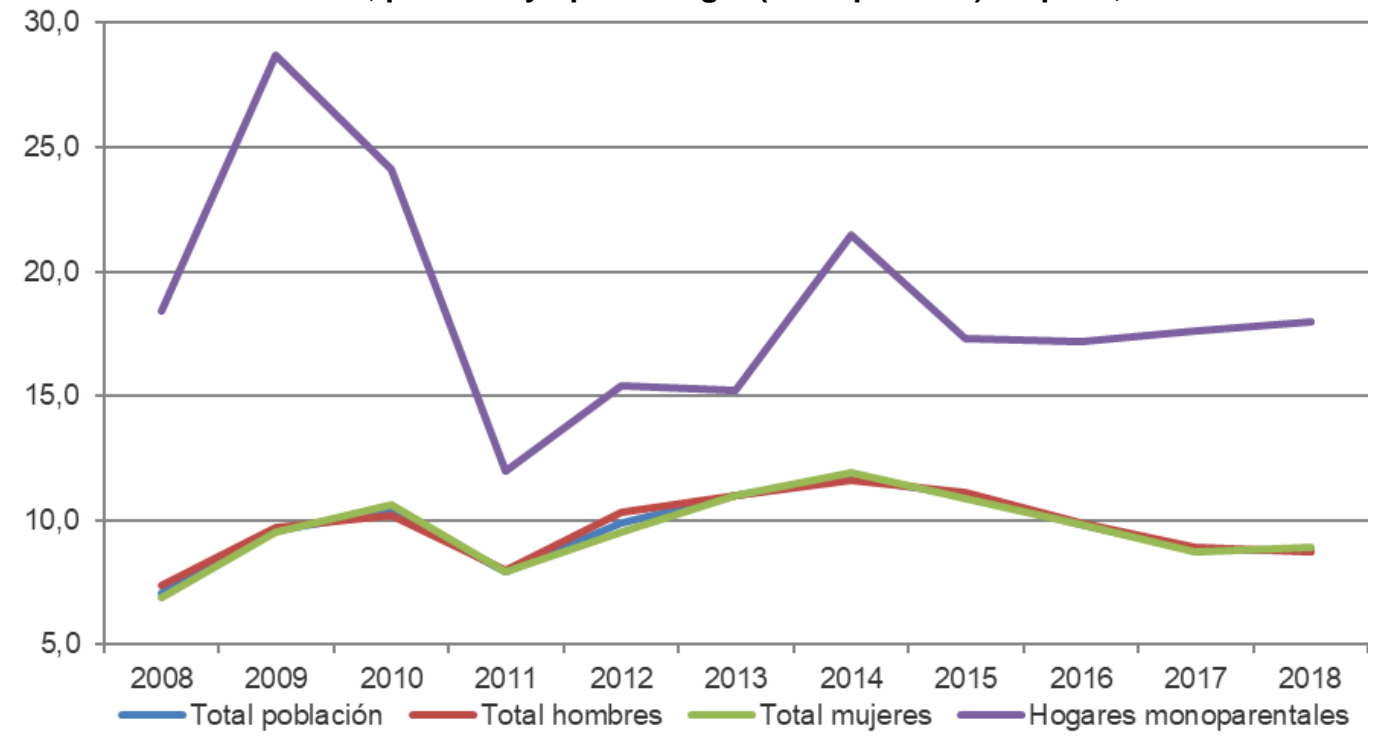

Fuente: Encuesta de Condiciones de Vida, Instituto Nacional de Estadística (INE).

Figura 5. Evolución del porcentaje de población que manifiesta no poder mantener la vivienda a una temperatura adecuada, por sexo y tipo de hogar (monoparental). España, 2008-2018.

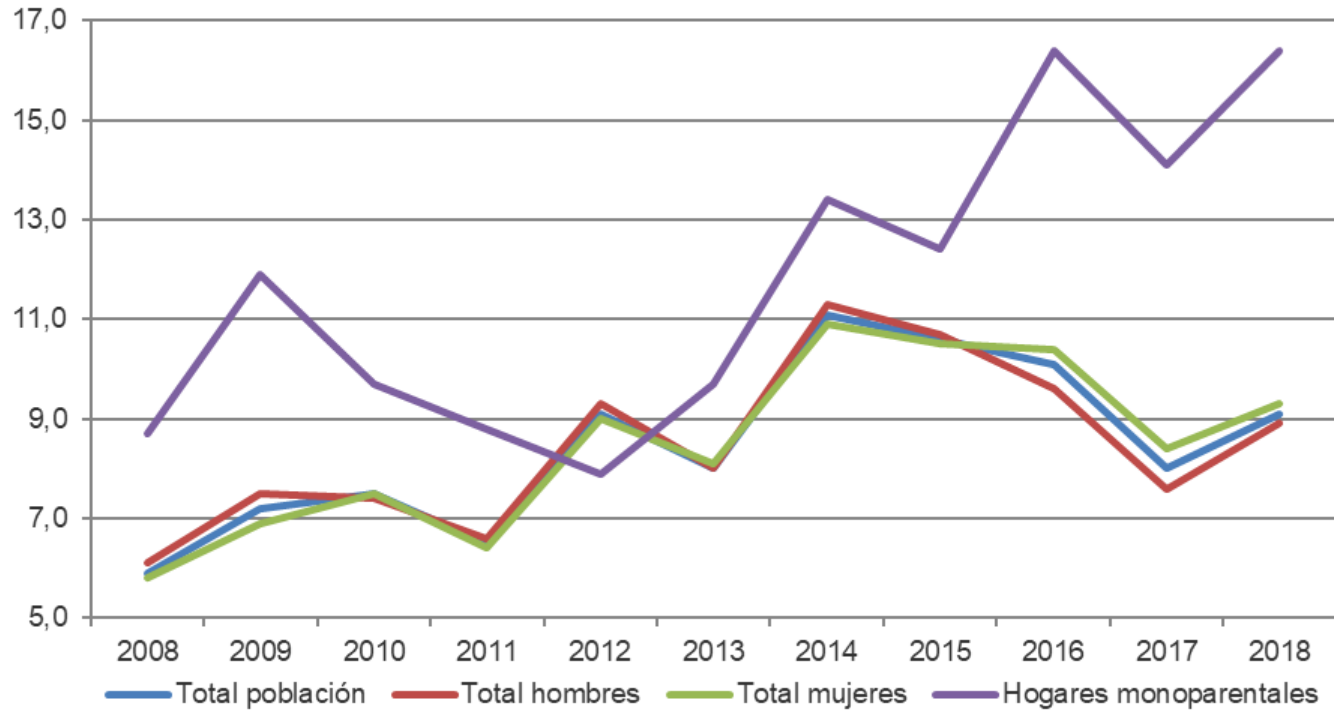

Fuente: Encuesta de Condiciones de Vida, Instituto Nacional de Estadística (INE).

Por otro lado, la Encuesta sobre Integración y Necesidades Sociales de 2018 (EINSFOESSA) llevada a cabo por la Fundación FOESSA nos permite examinar las actuales condiciones residenciales en términos económicos y físicos de los hogares encabezados por una mujer a través de indicadores distintos a los anteriores. Todos ellos muestran de forma incontestable las mayores dificultades que padecen estos hogares $y$, muy en particular, los monoparentales, para 


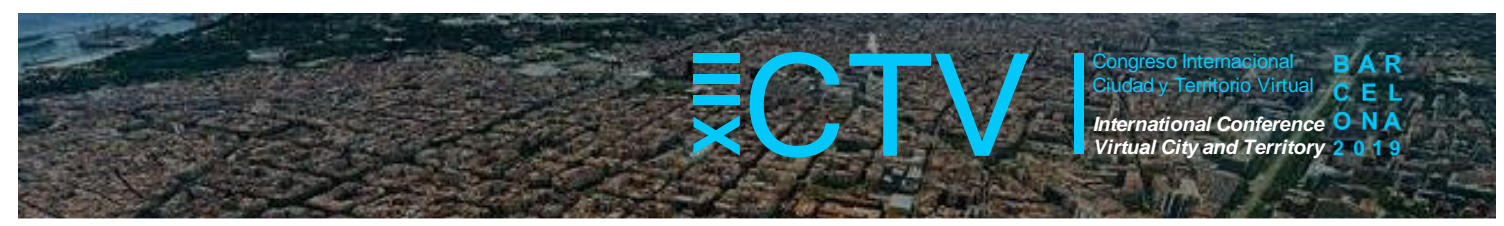

satisfacer los costes asociados a su vivienda, tales como una mayor frecuencia de: costes residenciales excesivos, retrasos en el pago de la hipoteca o el alquiler, recepción de avisos de corte de suministros, falta de recursos económicos para pagar los costes, o mayores riesgos de pérdida de la vivienda por impago (Tabla 1). Asimismo, los resultados de esta encuesta también muestran la mayor propensión de los hogares encabezados por una mujer a desarrollar estrategias residenciales con el propósito de reducir los costes de su vivienda como, por ejemplo, el subarriendo de habitaciones, bajos consumos de electricidad, agua o calefacción, o una mayor movilidad residencial en busca de viviendas más asequibles (Tabla 1).

Estas mayores dificultades de los hogares encabezados por una mujer para satisfacer los costes de la vivienda han sido constatadas por un creciente número de trabajos. Por ejemplo, respecto los desahucios y las ejecuciones hipotecarias, pese a la ausencia de estadísticas oficiales desagregadas por sexos, Amnistía Internacional España (2017) considera que la expansión de los desahucios en el parque de alquiler ha afectado de forma especial a las mujeres, sobre todo a madres solteras, mujeres que se encargan del cuidado de otras personas, inmigrantes, mujeres con discapacidad y víctimas de violencia de género. Sánchez (2015), tras examinar las quejas recibidas por el Defensor del Pueblo Andaluz, detectó un incremento notable de los desahucios, ya sea por impago del crédito hipotecario o del alquiler, entre los hogares encabezados por una mujer con cargas familiares. El estudio llevado a cabo en Álava por Garcia y Etxezarreta (2018) también confirma la mayor incidencia de las ejecuciones hipotecarias y los desahucios entre las mujeres. Según Human Rights Watch, las mujeres cabeza de familia y las que están atadas por sus hipotecas a una ex pareja maltratadora u hostil constituyen dos grupos particularmente vulnerables en esta crisis (Sunderland, 2014).

Tabla 1. Indicadores de la dimensión económica de la exclusión residencial según sexo del sustentador del hogar y tipo de hogar (monoparental). España, 2018

\begin{tabular}{|c|c|c|c|c|}
\hline Coste mensual de la vivienda (1) & $\begin{array}{l}\text { Total hogares } \\
366 €\end{array}$ & $\begin{array}{c}\text { Hogares cuyo } \\
\text { sustentador } \\
\text { principal es } \\
\text { hombre } \\
374 €\end{array}$ & $\begin{array}{c}\text { Hogares cuyo } \\
\text { sustentador } \\
\text { principal es } \\
\text { mujer } \\
351 €\end{array}$ & $\begin{array}{c}\text { Hogares } \\
\text { monoparentales } \\
419 €\end{array}$ \\
\hline $\begin{array}{l}\text { Hogares cuyos gastos en vivienda son } \\
\text { excesivos (\%) (2) }\end{array}$ & 9,5 & 8,5 & 11,5 & 29,4 \\
\hline $\begin{array}{l}\text { Hogares que se han retrasado una o } \\
\text { más veces en el pago del alquiler o la } \\
\text { hipoteca en el último año (\%) } \\
\text { Hogares que han recibido alqún aviso }\end{array}$ & 5,8 & 5,3 & 6,8 & 16,5 \\
\hline $\begin{array}{l}\text { de corte de luz, agua o teléfono en el } \\
\text { último año (\%) }\end{array}$ & 7,0 & 6,7 & 7,8 & 20,3 \\
\hline $\begin{array}{l}\text { Hogares que no disponen de dinero } \\
\text { suficiente para pagar el coste de la } \\
\text { vivienda (hipoteca, alquiler, o } \\
\text { servicios) (\%) }\end{array}$ & 12,1 & 11,4 & 13,5 & 25,0 \\
\hline $\begin{array}{l}\text { Hogares que han sufrido algún tipo de } \\
\text { amenaza de expulsión de su vivienda } \\
\text { (inmediata o no) (\%) } \\
\text { Hogares que por problemas }\end{array}$ & 2,0 & 1,8 & 2,4 & 8,2 \\
\hline $\begin{array}{l}\text { económicos han reducido los gastos } \\
\text { fijos del hogar (electricidad, agua, } \\
\text { calefacción) (\%) } \\
\text { Hogares que por problemas }\end{array}$ & 22,6 & 20,9 & 25,8 & 40,7 \\
\hline $\begin{array}{l}\text { económicos se han visto obligados a } \\
\text { cambiar de vivienda (\%) } \\
\text { Hogares que por problemas }\end{array}$ & 1,9 & 1,6 & 2,6 & 7,5 \\
\hline $\begin{array}{l}\text { económicos comparten piso con otras } \\
\text { personas sin parentesco (\%) }\end{array}$ & 1,5 & 1,2 & 1,9 & 2,5 \\
\hline
\end{tabular}




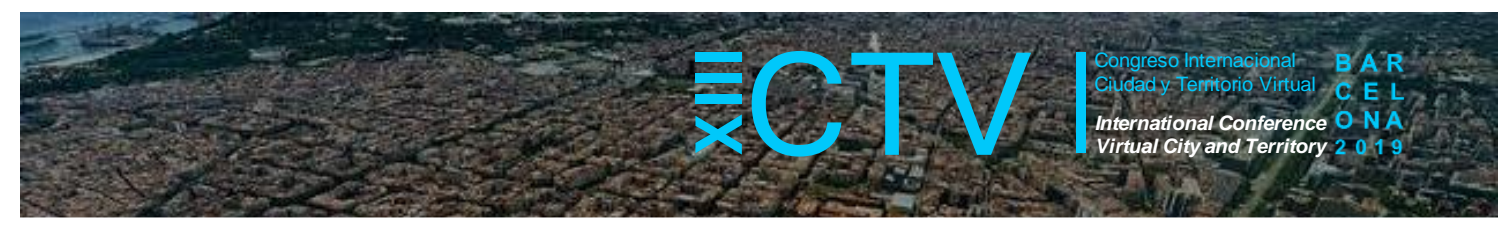

Hogares que por problemas

económicos han alquilado alguna

0,9

0,7

1,3

3,6

habitación a otras personas (\%)

Hogares que no pueden mantener su

vivienda con una temperatura

16,6

14,8

20,1

34,1

(1) Incluye el coste del alquiler o la amortización de la hipoteca, los servicios de agua, electricidad, gas, comunidad, contribución, basuras y demás servicios.

(2) Se considera como gastos de vivienda excesivos cuando estos hacen reducir los ingresos del hogar por debajo del umbral pobreza extrema.

Fuente: Encuesta sobre Integración y Necesidades Sociales de 2018 (EINSFOESSA), Fundación FOESSA (Arrondo y Bosch, 2019).

Las investigaciones de la Plataforma de Afectados por la Hipoteca también son concluyentes al respecto. En su informe sobre la emergencia habitacional en España (ODESC/PAH, 2013) basado en más de 11 mil encuestas, un $54 \%$ de los hogares afectados por ejecuciones hipotecarias estaba compuesto por padres y/o madres con hijos a su cargo, y un 30\% tenía una o más personas mayores a su cargo, de lo que cabe deducir una mayor proporción de mujeres entre las personas afectadas dado su rol en el hogar como cuidadora, y por la feminización de la vejez. En su informe sobre Cataluña (ODESC/PAH, 2015), de las cerca de mil personas encuestadas, un $62 \%$ eran mujeres. $Y$ su trabajo equivalente circunscrito a la ciudad de Barcelona (ODESC/PAH, 2016, pág. 56), un 52\% de las 957 personas que respondieron el cuestionario. Más recientemente, la serie de trabajos sobre el derecho a la vivienda y la salud en Barcelona aporta datos aún más reveladores: las mujeres representan entre el $68 \%$ (ODESC/PAH, 2018a, pág. 25) y el 72\% (ODESC/PAH, 2018b, pág. 43; 2018c, pág. 17) de las personas encuestadas; un $15 \%$ de los hogares en situación de inestabilidad residencial (en proceso de desahucio o con tres meses de impago) eran mujeres que vivían solas, un $25 \%$ hogares monoparentales, y un $36 \%$ parejas con hijos (ODESC/PAH, 2018b, pág. 55); y un $70 \%$ de las ayudas concedidas en Barcelona en 2015 para situaciones de pobreza energética fueron solicitadas por mujeres (ODESC/PAH, 2018b, pág. 57).

\subsection{La dimensión física}

Lógicamente, la peor situación socioeconómica de los hogares encabezados por una mujer conlleva también en unas inferiores condiciones residenciales pues con mayor frecuencia se ven obligadas a vivir en el segmento de mercado más asequible, por lo general, ubicado en entornos física y socialmente más degradados.

A lo largo del periodo 2008-2018, la proporción de hogares encabezados por una mujer que manifestaba sufrir algún tipo de problema en su vivienda fue sistemáticamente mayor que entre los encabezados por hombres, tanto a nivel global (Figura 6), como en problemas concretos como: la falta de luz natural en la vivienda (Figura 7), la contaminación u otros problemas ambientales (Figura 8), el ruido (Figura 9), o la delincuencia y el vandalismo (Figura 10).

Tales resultados son coherentes con estudios anteriores. De acuerdo con el módulo específico de vivienda de la Encuesta de Condiciones de Vida de 2012 sobre satisfacción residencial, en 2012 un 12,9\% de las mujeres manifestaba sentirse insatisfecha o muy insatisfecha con su vivienda frente al $11,2 \%$ de los hombres; y el porcentaje de mujeres que ese mismo año afirmaba sufrir falta de espacio en su vivienda era mayor entre las mujeres que entre los hombres. De igual modo, un estudio anterior basado en el Censo de 2001 denunciaba que (Bosch 2006, 36): "[...] las condiciones residenciales de los hogares encabezados por una mujer son, 


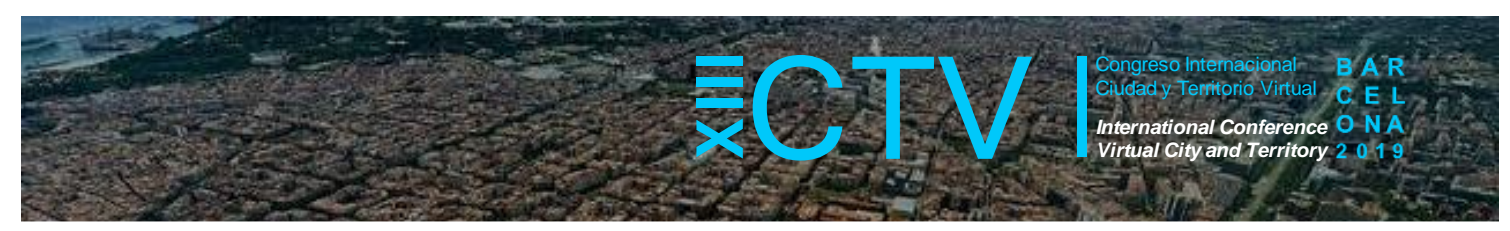

comparativamente y por lo general, peores: viviendas más antiguas, peor equipadas $y$ conservadas y con mayor tendencia al alquiler como régimen de tenencia asociado a la precariedad socioeconómica."

Figura 6. Evolución del porcentaje de hogares que manifiesta no sufrir ningún problema en su vivienda por sexo de la persona de referencia y hogares monoparentales. España, 2008-2018

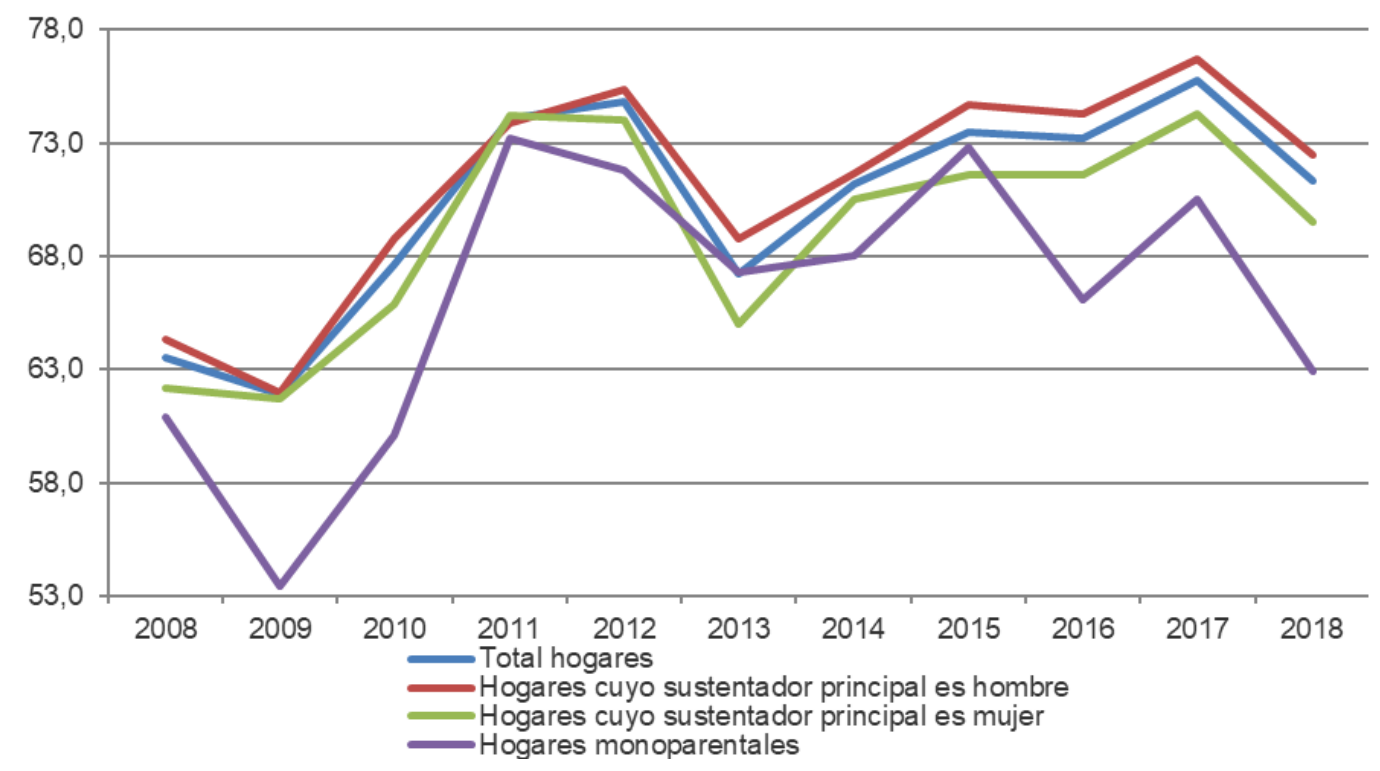

Fuente: Encuesta de Condiciones de Vida, Instituto Nacional de Estadística (INE).

Figura 7. Evolución del porcentaje de hogares que manifiesta sufrir escasez de luz natural en su vivienda por sexo de la persona de referencia y hogares monoparentales. España, 2008-2018

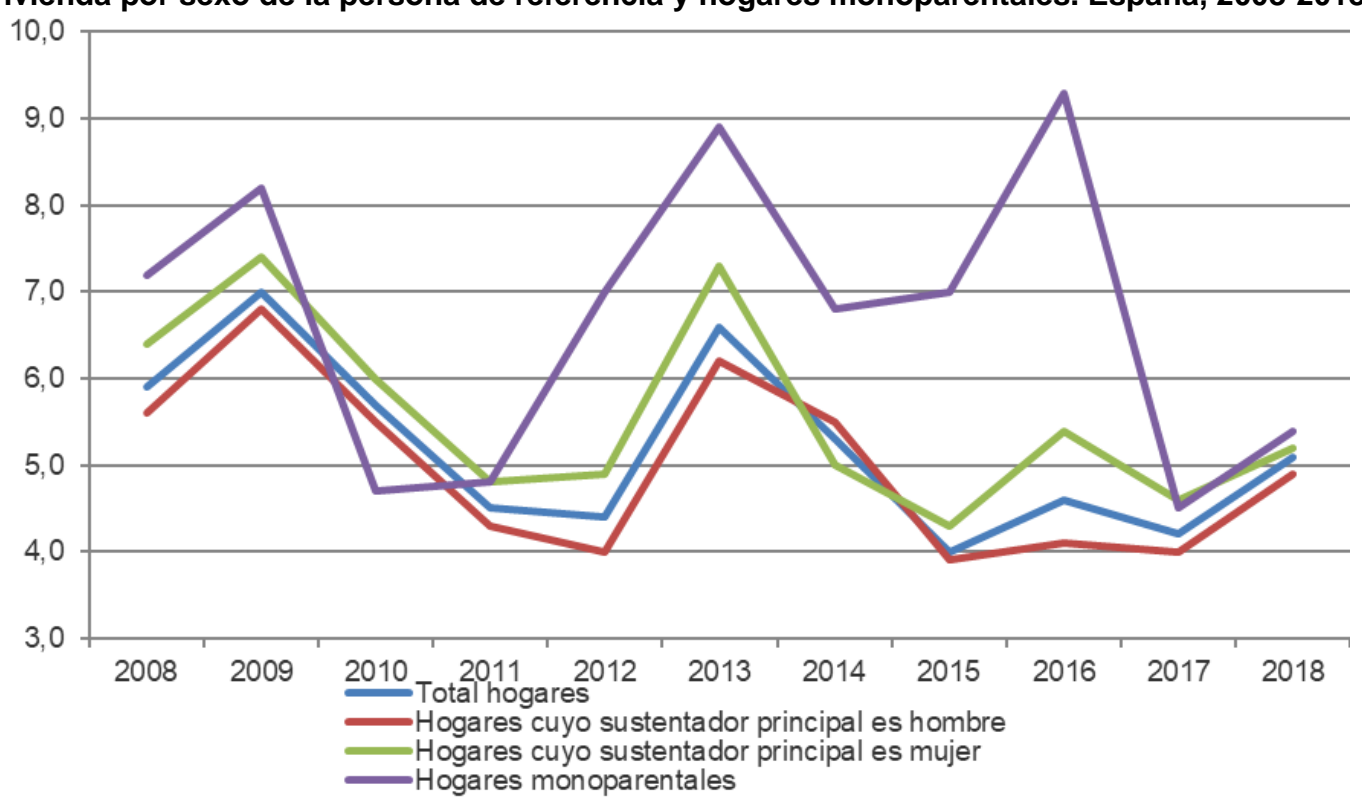

Fuente: Encuesta de Condiciones de Vida, Instituto Nacional de Estadística (INE).

Y al igual que sucedía en la dimensión económica, estos indicadores de la dimensión física de la exclusión residencial son, por lo general, superiores entre los hogares monoparentales, viniendo a corroborar su extendida precariedad residencial. 


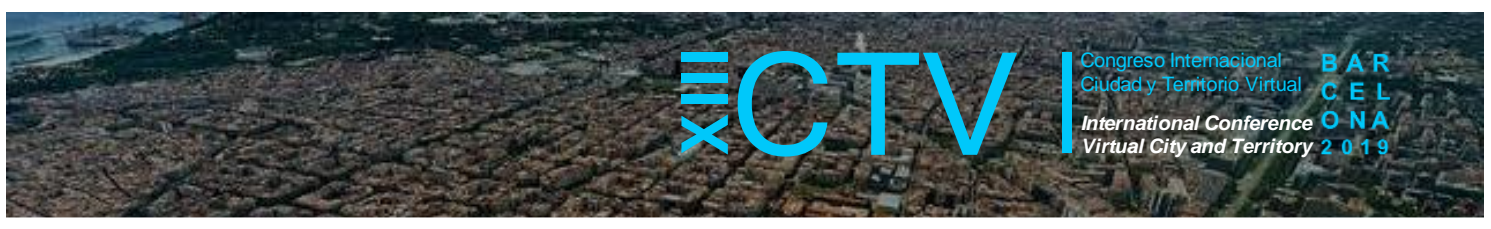

Figura 8. Evolución del porcentaje de hogares que manifiesta sufrir en su vivienda o su entorno problemas de contaminación u otros problemas ambientales por sexo de la persona de referencia y hogares monoparentales. España, 2008-2018

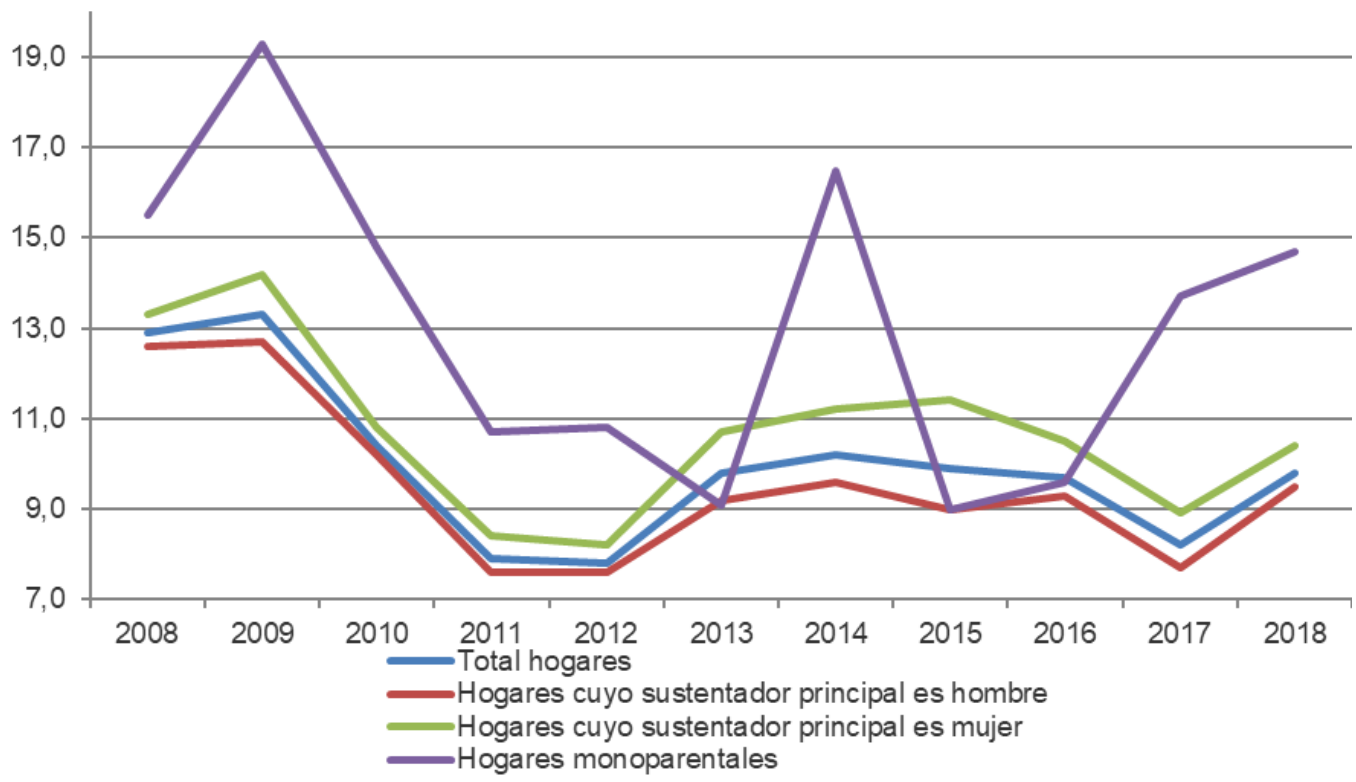

Fuente: Encuesta de Condiciones de Vida, Instituto Nacional de Estadística (INE).

Figura 9. Evolución del porcentaje de hogares que manifiesta sufrir en su vivienda problemas de ruidos producidos por vecinos o del exterior por sexo de la persona de referencia y hogares monoparentales. España, 2008-2018

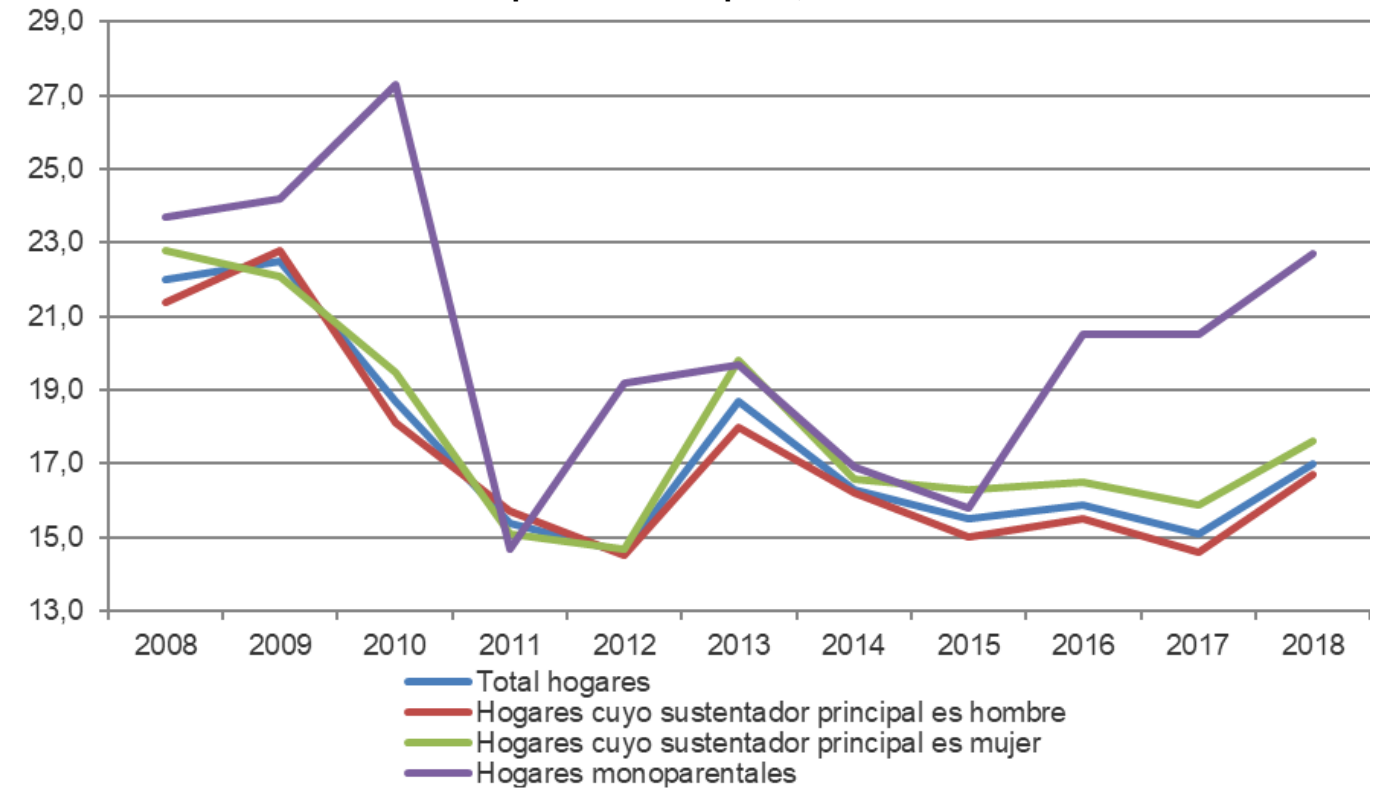

Fuente: Encuesta de Condiciones de Vida, Instituto Nacional de Estadística (INE).

Los resultados de la Encuesta EINSFOESSA relativos a las condiciones físicas de la vivienda según el sexo de la persona de referencia corroboran la mayor incidencia de problemas residenciales entre las mujeres en aspectos como: la insalubridad, las necesidades de rehabilitación, la existencia de barreras arquitectónicas, y la ausencia de ascensor en edificios plurifamiliares (Tabla 2). No obstante, hay que subrayar que, en este caso, las viviendas de los 


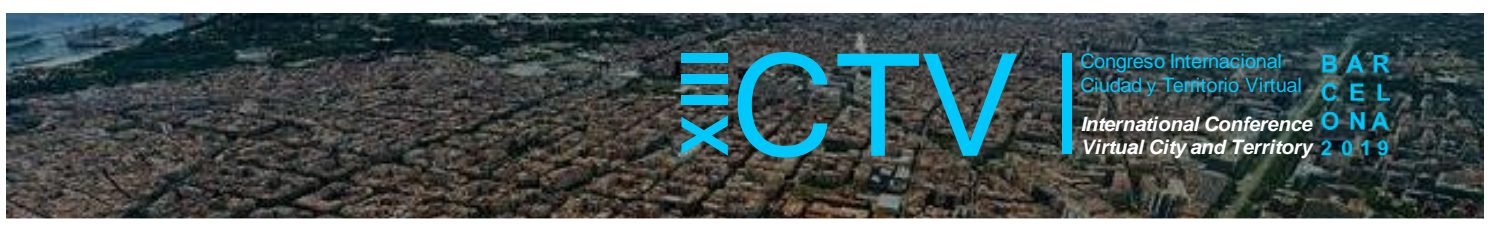

hogares monoparentales, aunque peores que las del conjunto de la población, no son inferiores a las de los hogares sustentados por una mujer, excepto en la disponibilidad de ascensor en el edificio (Tabla 2).

Figura 10. Evolución del porcentaje de hogares que manifiesta sufrir en el entorno de su vivienda problemas de delincuencia o vandalismo por sexo de la persona de referencia y hogares monoparentales. España, 2008-2018

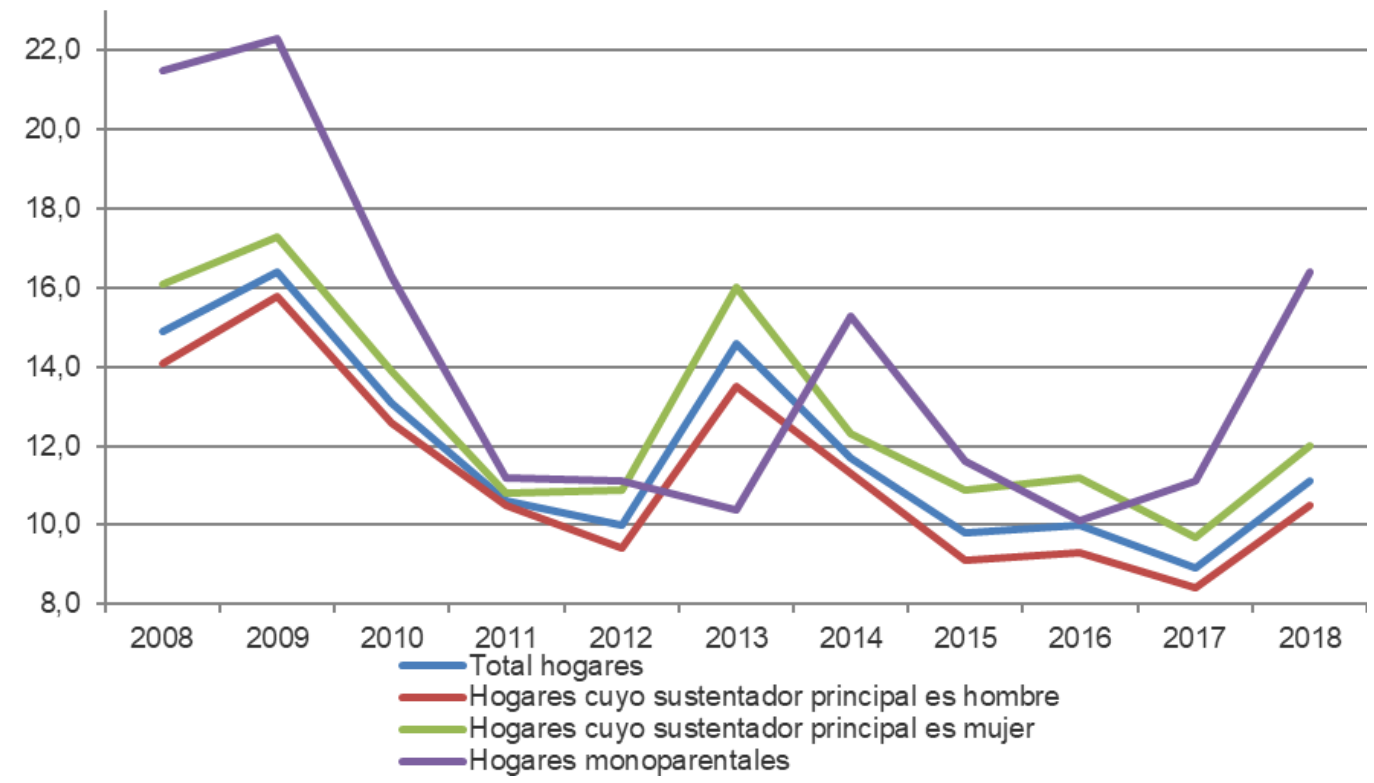

Fuente: Encuesta de Condiciones de Vida, Instituto Nacional de Estadística (INE).

Tabla 2. Indicadores de la dimensión física de la exclusión residencial según sexo del sustentador del hogar y tipo de hogar (monoparental). España, 2018

\begin{tabular}{lcccc}
\hline & $\begin{array}{c}\text { Total } \\
\text { hogares }\end{array}$ & $\begin{array}{c}\text { Hogares cuyo } \\
\text { sustentador principal } \\
\text { es hombre }\end{array}$ & $\begin{array}{c}\text { Hogares cuyo } \\
\text { sustentador } \\
\text { principal es mujer }\end{array}$ & $\begin{array}{c}\text { Hogares } \\
\text { monoparentales }\end{array}$ \\
\hline $\begin{array}{l}\text { Hogares cuya vivienda sufre } \\
\text { problemas de insalubridad } \\
\text { (humedad, suciedad, olores) (\%) }\end{array}$ & 6,8 & 6,1 & 8,1 & 7,9 \\
\hline $\begin{array}{l}\text { Hogares cuya vivienda presenta } \\
\text { barreras arquitectónicas graves } \\
\text { para personas con minusvalía (\%) }\end{array}$ & 3,7 & 2,9 & 5,3 & 3,9 \\
$\begin{array}{l}\text { Hogares cuya vivienda necesita } \\
\text { ser rehabilitada (\%) }\end{array}$ & 5,2 & 4,3 & 7,1 & 6,9 \\
\hline $\begin{array}{l}\text { Hogares que viven en un edificio } \\
\text { plurifamiliar que no dispone de } \\
\text { ascensor (\%) }\end{array}$ & 27,2 & 25,8 & 29,7 & 38,7 \\
\hline
\end{tabular}

Fuente: Encuesta sobre Integración y Necesidades Sociales de 2018 (EINSFOESSA), Fundación FOESSA (Arrondo y Bosch, 2019).

\section{Conclusiones}

A pesar de las dificultades metodológicas para examinar en España la exclusión residencial desde una perspectiva de género, tanto la explotación de la limitada información estadística disponible que permite este tipo de análisis como los trabajos de corte cualitativo llevados a cabo en los últimos años son concluyentes: el estallido de la burbuja residencial y la posterior recesión económica provocaron una grave crisis residencial que ha afectado con mayor intensidad a las mujeres. 


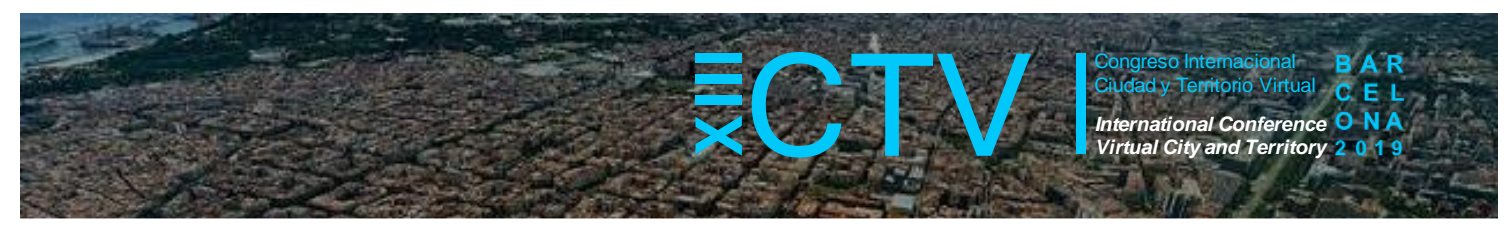

La dimensión económica de esta feminización de la exclusión residencial es particularmente visible en la evolución de la relación entre ingresos del hogar y costes residenciales. Durante todo el periodo 2008-2018, el esfuerzo económico de las mujeres para satisfacer sus costes residenciales así como, por lo general, su tasa de sobresfuerzo económico, fueron superiores al de los hombres. Por ello, en buena lógica, la incidencia de los desahucios ha sido mayor entre aquellos encabezados por mujeres, sobre todo entre los hogares monoparentales, entre las mujeres que viven solas en alquiler, y entre las que deben afrontar elevados pagos hipotecarios. Y por idénticos motivos, estos hogares tienen una mayor propensión a desarrollar estrategias residenciales orientadas a reducir los costes de su vivienda como, por ejemplo, el subarriendo de habitaciones, bajos consumos de electricidad, agua o calefacción, o una mayor movilidad residencial en busca de viviendas más asequibles.

Esta peor situación de la mujer en el mercado residencial también queda reflejada en las condiciones físicas de la vivienda y en su entorno. Las viviendas de los hogares encabezados por una mujer suelen sufrir con mayor frecuencia: problemas de insalubridad, escasez de luz natural, déficits de rehabilitación, y existencia de barreras arquitectónicas. Además, en los barrios donde viven son mayores los problemas de contaminación, ruido, vandalismo y delincuencia.

Llegados a este punto, resulta oportuno reflexionar sobre la eficacia del conjunto de documentos políticos y jurídicos que a nivel nacional e internacional exhortan a los gobiernos a garantizar el derecho de la mujer a una vivienda digna y adecuada. ¿Cómo puede explicarse que el derecho de la mujer a la vivienda en España haya alcanzado semejantes cotas de vulneración a pesar de la extensa relación de tratados y convenciones internacionales que lo protegen y que son de aplicación en el territorio español? Es evidente que no existen medidas suficientes que corrijan la feminización de la exclusión residencial en España. Es más, probablemente los recortes de gasto público que se han llevado a cabo en España tras la crisis no han hecho más que socavar las de por si débiles políticas de igualdad y de vivienda de nuestro país, y por extensión, ensanchar la brecha de género (gender gap) en materia de exclusión residencial. Por todo ello, resulta obvio que, actualmente, el principal reto no radica en insistir en el plano teórico-declarativo del reconocimiento del derecho a la vivienda y a la igualdad entre hombres y mujeres, sino en conseguir que estas políticas se implementen, se doten presupuestariamente con los recursos necesarios, se asuman compromisos, y se fijen objetivos concretos y mensurables que permitan su seguimiento y evaluación.

Conflicto de Intereses: El autor declara que no hay conflicto de intereses.

\section{Bibliografía}

Amnistía Internacional España (2017). La crisis de vivienda no ha terminado. El derecho a la vivienda y el impacto de los desahucios de viviendas de alquiler sobre las mujeres en España. Recuperado de https://www.es.amnesty.org/uploads/media/Inf.Vivienda FIN2.pdf

Arrondo, M. y Bosch J. (2019). La exclusión residencial en España, Documento de trabajo 3.3. para el VIII Informe FOESSA. Recuperado de www.foessa.es/viii-informe/capitulo3.

Bosch, J. (2006). El problema de la vivienda en España desde una perspectiva de género: análisis y propuestas para su desarrollo. Madrid, España: Fundación Alternativas. 


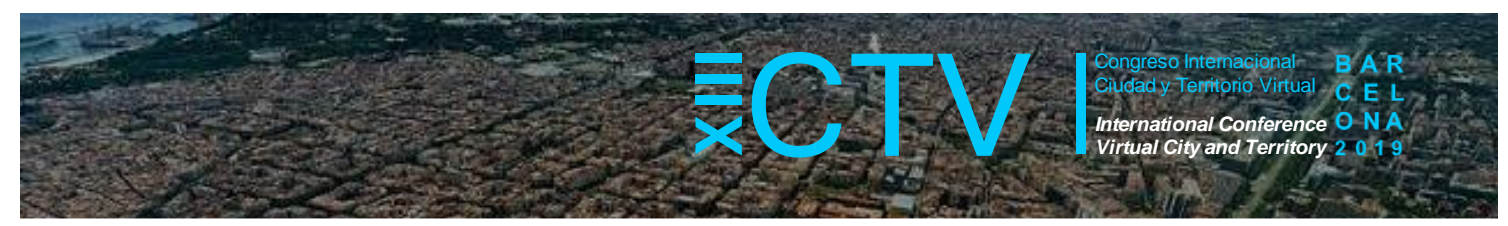

Bosch, J. (2015). Crisis y emancipación juvenil en Europa. Un análisis desde los modelos de Estado de Bienestar. Vitoria-Gasteiz, España: Servicio Central de Publicaciones del Gobierno Vasco.

COHRE (2010). Un lugar en el mundo. El derecho a una vivienda adecuada como elemento esencial de una vida libre de violencia doméstica. Los casos de Argentina, Brasil y Colombia. Ginebra, Suiza: Center on Housing Rights and Evictions (COHRE).

Emanuelli, M. S. (Ed). Vivienda con rostro de mujer: mujeres y derecho a una vivienda adecuada. México, México: Social Watch, Coalición Internacional para el Hábitat, Oficina Regional para América Latina (HIC-AL) y Red Mujer y Hábitat América Latina.

Farha, L. (2015). Informe de la Relatora Especial sobre una vivienda adecuada como elemento integrante del derecho a un nivel de vida adecuado y sobre el derecho de no discriminación a este respecto. Nueva York, Estados Unidos: Asamblea General de Naciones Unida.

García, A. y Etxezarreta, A. (2018). Un estudio de caso de los desahucios a nivel local: el caso de stop desahucios Araba. Revista de Economía Crítica, n. 25, pp. 26-46.

Kennett, P. y Kam, C. (Eds) (2010). Women and Housing. Oxon, Reino Unido: Taylor \& Francis. Kothari, M. (2006). La mujer y la vivienda adecuada. Informe del Relator Especial sobre una vivienda adecuada como elemento integrante del derecho a un nivel de vida adecuado y sobre el derecho de no discriminación a este respecto. Nueva York, Estados Unidos: Consejo Económico y Social, Naciones Unidas.

ODESC/PAH (2013). Emergencia habitacional en el estado español: la crisis de las ejecuciones hipotecarias y los desalojos desde una perspectiva de derechos humanos. Barcelona, España: Observatorio Derechos Humanos DESC y Plataforma de Afectados por la Hipoteca.

ODESC/PAH (2015). Emergència habitacional a Catalunya. Impacte de la crisi hipotecària en el dret a la salut i els drets dels infants. Barcelona, España: Observatorio Derechos Humanos DESC y Plataforma de Afectados por la Hipoteca.

ODESC/PAH (2016). Exclusió residencial al món local Informe de la crisi hipotecària a Barcelona (2013-2016). Barcelona, España: Observatorio Derechos Humanos DESC y Plataforma de Afectados por la Hipoteca.

ODESC/PAH (2018a). Radiografies de la situació del dret a l'habitatge, la pobresa energètica $i$ el seu impacte en la salut a Barcelona. Informe I. Informe sobre la situació del dret a l'habitatge, la pobresa energètica $i$ el seu impacte en la salut a Barcelona. Recuperado de https://pahbarcelona.org/wp-content/uploads/2018/03/Estudi-Salut-ODESC-alta.pdf

ODESC/PAH (2018b). Radiografies de la situació del dret a l'habitatge, la pobresa energètica $i$ el seu impacte en la salut a Barcelona Informe II. Perspectiva de gènere sobre el dret a l'habitatge i la pobresa energètica a Barcelona. Recuperado de https://pahbarcelona.org/wpcontent/uploads/2018/10/Estudi-Genere-ASPB-ODESC-ESF-alta.pdf 


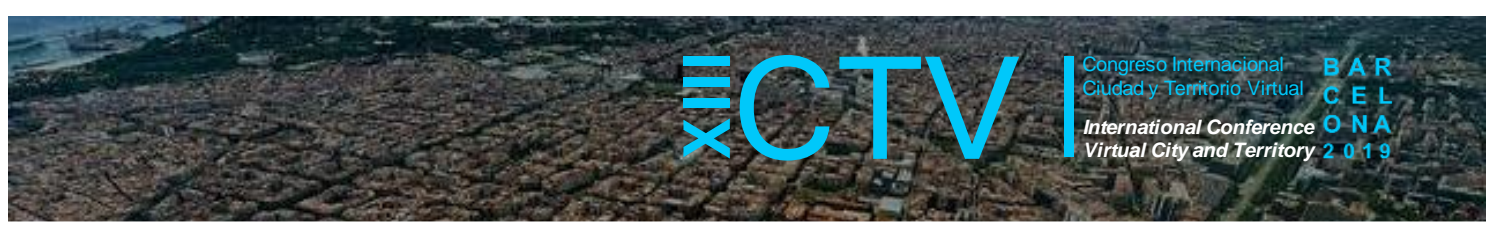

ODESC/PAH (2018c). Radiografies de la situació del dret a l'habitatge, la pobresa energètica i el seu impacte en la salut a Barcelona Informe III. Una mirada en profunditat a la salut de les persones afectades per l'accés a l'habitatge $i$ la pobresa energética. Recuperado de https://www.aspb.cat/wp-content/uploads/2019/02/Radiografies-Dret-Habitatge-PobresaEnergetica-Salut-Barcelona-3.pdf

Rolnik, R. (2011). Informe de la Relatora Especial sobre una vivienda adecuada como elemento integrante del derecho a un nivel de vida adecuado y sobre el derecho de no discriminación a este respecto. Nueva York, Estados Unidos: Asamblea General de Naciones Unidas.

Sánchez, M. I. (2015). Sinhogarismo de las familias monomarentales. En Actas del V Congreso universitario internacional investigación y género, (pp. 214-225). Sevilla, España: Universidad de Sevilla.

Sunderland, J. (2014). Sueños rotos. El impacto de la crisis española de la vivienda en grupos vulnerables. Recuperado de https://www.hrw.org/sites/default/files/reports/spain0514sp ForUpload 0.pdf

Tually, S.; Beer, A. y Faulkner, D. (2007). Too Big to Ignore: Future Issues for Australian Women's Housing 2006-2025. Melbourne, Australia: Australian Housing and Urban Research Institute (AHURI).

UN-Habitat (2005). Report on the Central-Asia/Eastern Europe Regional Consultation on Women's Right to Adequate Housing. The interlinkages between multiple discrimination and Women's Right to Adequate Housing. Budapest, Hungría: United Nations Human Settlements Programme.

UN-Habitat (2014). Women and Housing: Towards Inclusive Cities. Nairobi, Kenia: UN-Habitat.

UN-Human Rights (2012). Women and the right to adequate housing. Nueva York, Estados Unidos: The United Nations Office of the High Commissioner for Human Rights. 